\title{
Accuracy of clinical diagnosis, mammography and ultrasonography in preoperative assessment of breast cancer
}

\author{
Augustina Badu-Peprah ${ }^{1,2}$ and Yaw Adu-Sarkodie ${ }^{1,2}$
}

Ghana Med J 2018; 52(4): 235-241 doi: http://dx.doi.org/10.4314/gmj.v52i4.11

\author{
${ }^{1}$ Komfo Anokye Teaching Hospital, Kumasi Ghana, \\ ${ }^{2}$ Kwame Nkrumah University of Science and Technology, Kumasi, Ghana
}

Corresponding author: Dr. Augustina Badu-Peprah

E-mail: augustinabadupeprah@gmail.com

Conflict of interest: None declared

\begin{abstract}
SUMMARY ogy results were retrieved to complete the study. mogram and ultrasound were $73.0 \%, 80.0 \%$ and $100 \%, 80.4 \%$ respectively. potentially predict breast cancer disease with considerable sensitivity and specificity.

Funding: None declared

Keywords: Mammography, ultrasonography, histology, breast cancer.
\end{abstract}

Background: Cancer of the breast is the most common malignancy affecting women in many parts of the world, hence its early detection has become necessary to reduce morbidity and mortality from the disease. In sub-Saharan Africa, radiological imaging, histology and management programs are associated with challenges. This study seeks to assess the validity of clinical diagnosis, mammography and breast ultrasonography in the preoperative assessment of suspected breast cancer patients for accurate detection of the disease to enable appropriate management.

Methods: A prospective cross-sectional study was carried out in the Radiology Department of Komfo Anokye Teaching Hospital, Kumasi, Ghana, between November 2007 and July 2008 with a sample size of 103. All patients with a clinical suspicion of breast cancer who gave informed consent were recruited, underwent bilateral mammography and whole breast ultrasonography and then biopsy for all BI-RADS categories 4 or 5 lesions. The histopathol-

Result: In this study the definition of malignancy was made using histology as the gold standard. A total of 103 patients were recruited for this study with mean age of $55(+15)$ years, out of which $52(50.5 \%)$ had malignant lesions. The overall sensitivity of clinical diagnosis was $50.5 \%$. While the overall sensitivity and specificity for mam-

Conclusion: In conclusion, this study has demonstrated that clinical diagnosis, ultrasound and mammography can

\section{INTRODUCTION}

The accuracy of clinical diagnosis, mammography and breast ultrasonography in the preoperative assessment of breast cancer is necessary for early diagnosis. It is also to allow accurate pre-treatment planning and allow neoadjuvant chemotherapy or a single surgical intervention with clear surgical margins to reduce the incidence of tumour recurrence as patients usually abscond after the first surgical intervention. Cancer of the breast is the most common malignancy affecting women in many parts of the world. ${ }^{1,3,4}$

About $16 \%$ of the world's population is covered by registration systems that produce cancer incidence statistics, while mortality data are available for about $29 \%{ }^{1}$ Breast cancer incidence and mortality vary considerably by world regions. In general, the incidence is high (greater than 80 per 100,000) in developed regions of the world and low (less than 30 per 100,000), though increasing, in developing regions.
The range of mortality rates is much less (approximately 6-23 per 100,000) because of the more favorable survival of breast cancer in high-incidence developed regions. ${ }^{5}$ The low incidence in developing regions maybe attributed to poor and/or lack of cancer registry and data collection which has however started improving in the last decade. The incidence of female breast cancer is increasing almost everywhere. ${ }^{6}$ This unfavorable trend is due in part to increases in risk factors such as decreased childbearing and breast-feeding, increased exogenous hormone exposure, and detrimental dietary and lifestyle changes, including obesity and less physical activity, early menarche and late menopause. . $^{7,9}$

On the other hand, mortality is now decreasing in many high-risk countries due to a combination of intensified early detection efforts and the introduction of mammographic screening, resulting in the diagnosis of more smaller, early stage tumors, and advances in treatment. ${ }^{10}$ 
In a ten year review in Korle Bu Teaching Hospital, the commonest cause of cancer death in females was malignancies of the breast [Age-Standardized Cancer Ratio (ASCAR), 17.24\%]. ${ }^{4}$

At the Komfo Anokye Teaching Hospital (KATH), Kumasi, Ghana, where this study took place, breast cancer formed the highest percentage of cancers $(23 \%)$ in the annual cancer registry at the oncology unit for the year 2006. A realistic strategy for the reduction in breast cancer mortality rates is to accurately diagnose the disease while it is still in an early stage. Mass screening for breast cancer, using mammography has demonstrated a $30 \%$ reduction in breast cancer mortality in Western countries $^{11}$ and has also shown a significant $33 \%$ reduction in mortality rates for the high-risk group in Taiwan. $^{12}$

In Ghana, there is no established national breast screening program, but there is however increasing awareness through educational campaigns. This awareness has increased the number of women seeking medical help with symptoms of breast disease. ${ }^{13}$ It is therefore appropriate for physicians to make good clinical judgment to suspect breast cancer through clinical history and clinical examination to assist in early detection of the disease.

Conventional mammography and sonography of the breast are used as routine imaging techniques in diagnosis of breast cancer throughout the world. The sensitivity of mammographic detection of cancer is high but is reduced in women with radiographically dense breasts, because breast cancers have a radiographic attenuation that is similar to that of glandular and fibrous elements. ${ }^{3}$ The sensitivity of mammography to the index cancer ranges from $63 \%$ to $98 \%{ }^{15}$ and has been reported to be as low as $30 \%$ to $48 \%$ in dense breasts. ${ }^{16}$ hence reducing the accuracy of breast cancer diagnosis by mammography.

Several groups have evaluated the preoperative use of supplementary magnetic resonance (MR) imaging ${ }^{17}$ ultrasonography (USG) ${ }^{18}$, or both ${ }^{19}$ after mammography to assess the extent of disease within the breast(s). Generally, USG is very useful in differentiating the breast tumours from cystic lesions and is used an as adjunct tool to evaluate breast abnormalities found during mammography or physical examination.

However, Chao et al. ${ }^{20}$ have shown that USG has a high predictive ability when examining the breast per study done on Taiwan women. However, among high-risk women, USG in combination with other methods may play an important role in breast cancer imaging.
Also, with scarce radiological and/or economic resources for breast imaging in our setting, knowledge of appropriate features of breast cancer on imaging using the most cost-effective imaging modalities is essential for detection of breast cancer early enough for appropriate management. With increasing use of reliable percutaneous biopsy techniques, a current goal in breast cancer management is accurate pre-treatment planning to allow neoadjuvant chemotherapy or a single definitive surgical procedure with lymph node sampling. Complete excision of malignant foci is the standard, with the goal of achieving clear margins of excision.

The purpose of this study was then to prospectively assess the accuracy of clinical diagnosis, mammography and breast Ultrasonography in the preoperative assessment of breast cancer with histology as the gold standard.

\section{METHODS}

This was a prospective cross-sectional study using convenient sampling and a sample size of 103 patients. The study took place in Ghana, in the Radiology Department at Komfo Anokye Teaching Hospital (KATH) a 1200bed capacity hospital, located in Kumasi, the Regional Capital of Ashanti Region with a total projected population of 4,780,380 (2000). ${ }^{21}$

The study took place between November 2007 and July 2008. Ethical approval for the study was granted by the Committee on Human Research, Publication and Ethics of the School of Medical Sciences, Kwame Nkrumah University of Science and Technology.

The Department has 5 radiologists and 13 resident doctors and performs an average of 520 breast imaging cases annually out of which an average of $10 \%$ are breast cancers. All patients coming to the Radiology Department for breast imaging with a clinical suspicion of breast cancer who gave informed consent were recruited into the study. All age groups were considered, and the inclusion criteria was to have clinical suspicion of malignancy with a request for breast imaging. Those with no clinical suspicion for malignancy and patients who did not give informed consent were excluded from the study and this did not affect their management or care.

All the participants were interviewed, and a predesigned form was used to collect data on their sociodemographic status. Data from patient's notes were also taken to obtain their clinical history and clinical examination. At the radiology department, the women enrolled into the study underwent bilateral mammography and whole breast ultrasonography with the primary request from the surgeon being the first to be carried out. 
Records of findings were also recorded onto a predesigned form using Breast Imaging Reporting and Data System, or BIRADS, lexicon (Appendix I).

Biopsy was recommended if the mammogram or the sonographic findings were adjudged to be suspicious or highly suggestive for cancer, in accordance with (BIRADS) categories 4 or 5 . All cases with normal or benign radiological features were considered as normal and were not biopsied.

Mammogram was performed using dedicated mammographic equipment (Mammomat 300 1995, Siemens, Germany) and the screen film technique. Conventional four-view film mammograms included routine craniocaudal and mediolateral oblique views of the breast(s) and spot views when needed. Bilateral whole-breast ultrasonography was performed with knowledge of clinical and mammographic findings. All sonograms were obtained using high resolution diagnostic ultrasonography equipment (Siemens/Sonoline Sienna or Siemens/Sonoline G 50) and a 7.5-MHZ frequency transducer probe operated by an experienced physician. For the inner breast, scanning was performed with the patient in the supine position.

For the outer breast, the patient was placed in the contra lateral posterior oblique position with the ipsilateral arm raised. Survey scanning was performed in radial and anti-radial planes. Lesions were measured in both radial and anti-radial scanning planes and their location noted. Records of findings were recorded onto a predesigned form using Breast Imaging Reporting and Data System, or BIRADS, lexicon (Appendix I).

Lesions considered suspicious or highly suggestive of malignancy on mammography or ultrasonography were then sampled for core biopsy or excision biopsies after imaging. Preoperative core-needle biopsy was done under sonographic guidance for lesions that were too small or non-palpable. For bigger lesions biopsy was done blindly without any guidance. Biopsy was performed by one of the surgeons or radiologists.

A 14-gauge manual biopsy gun was used to sample lesions with a minimum of three passes per lesion. Histology results were retrieved from Pathology Department and it was the Gold standard for malignancy in this study. The data was double entered using Epi-info version 3.2.2 and cleaned for abnormal figures and values. The data was then transferred to R statistical software version 2.7.2 for analysis.

\section{RESULTS}

A total of 103 patients were recruited for this study with mean age of $55(+15)$ years and age range of 30-94 years, out of which $52(50.5 \%)$ had malignant lesions.
Clinical symptoms presented by participants were pain, mass, bloody nipple discharge and ulceration with frequencies of 77, 42, 8 and 3 respectively with some overlap of clinical symptoms. Seventeen of the participants with mass also had pain, four of those with bloody nipple discharge had mass as well and the three cases with ulceration had mass and pain at presentation (Table 1).

Table 1 Usefulness of clinical symptom for indicating diagnosis of malignancy of breast disease

\begin{tabular}{|l|l|l|l|l|l|l|l|}
\hline $\begin{array}{l}\text { Clinical } \\
\text { Symptoms }\end{array}$ & $\begin{array}{l}\text { Fre- } \\
\text { quency }\end{array}$ & $\begin{array}{l}\text { Sensi- } \\
\text { tivity } \\
\text { n\% }\end{array}$ & $\mathbf{9 5 \%}$ CI $^{*}$ & $\begin{array}{l}\text { Speci- } \\
\text { ficity } \\
\text { \% }\end{array}$ & $\mathbf{9 5 \%}$ CI $^{*}$ & $+\mathbf{P V}$ & -PV \\
\hline Pain & 77 & 71.2 & $56.9-82.9$ & 52.9 & $38.5-67.1$ & 60.7 & 64.3 \\
\hline Mass & 42 & 90.4 & $79.0-96.8$ & 41.2 & $27.6-55.8$ & 61.0 & 80.8 \\
\hline $\begin{array}{l}\text { Bloody } \\
\text { nipple } \\
\text { discharge }\end{array}$ & 8 & 98.1 & $89.7-99.7$ & 13.7 & $5.7-26.3$ & 53.7 & 87.5 \\
\hline Ulceration & 3 & 5.8 & $1.3-16.0$ & 100 & $92.8-100$ & 100 & 50.5 \\
\hline
\end{tabular}

The overall sensitivity of clinical diagnosis was $50.5 \%$. Seventy out of the 103 participants had menarche at age 15 and older out of which $31(44.3 \%)$ had malignant lesions while 33 had menarche before $15 y$ ears with 21 (63.7\%) having malignant lesions. Forty seven of the 103 participants were post-menopausal with 16 having malignant lesions and 56 participants being premenopausal with 36 having malignant lesions.

Table 2 Correlating proven malignant lesions to ultrasound and mammogram results

\begin{tabular}{|c|c|c|c|c|}
\hline \multirow[b]{2}{*}{ Impression } & \multicolumn{2}{|c|}{ Ultrasonography } & \multicolumn{2}{|c|}{ Mammography } \\
\hline & $\begin{array}{l}\text { true negative } \\
/ \\
\text { false positive } \\
(\%)\end{array}$ & $\begin{array}{l}\text { false nega- } \\
\text { tive / } \\
\text { true positive } \\
(\%)\end{array}$ & $\begin{array}{l}\text { true nega- } \\
\text { tive / false } \\
\text { positive } \\
(\%)\end{array}$ & $\begin{array}{l}\text { false nega- } \\
\text { tive / } \\
\text { true positive } \\
(\%)\end{array}$ \\
\hline $\begin{array}{l}\text { Category } 0 \\
\text { (needs additional } \\
\text { imaging evalua- } \\
\text { tion) }\end{array}$ & $0(0)$ & $0(0)$ & $11(64.7)$ & $6(35.3)$ \\
\hline $\begin{array}{l}\text { Category } 1 \\
\text { (negative- nothing } \\
\text { to comment on) }\end{array}$ & $32(100)$ & $0(0)$ & $25(100)$ & $0(0)$ \\
\hline $\begin{array}{l}\text { Category } 2 \\
\text { (Benign finding) }\end{array}$ & $3(100)$ & $0(0)$ & $5(100)$ & $0(0)$ \\
\hline $\begin{array}{l}\text { Category } 3 \\
\text { (Probably benign } \\
\text { finding) }\end{array}$ & $6(100)$ & $0(0)$ & $2(100)$ & $0(0)$ \\
\hline $\begin{array}{l}\text { Category } 4 \\
\text { (Suspicious ab- } \\
\text { normality) }\end{array}$ & $8(20)$ & $32(80)$ & $8(28.6)$ & $20(71.4)$ \\
\hline $\begin{array}{l}\text { Category } 5 \\
\text { (Highly sugges- } \\
\text { tive of malignan- } \\
\text { cy) }\end{array}$ & $2(9.1)$ & $20(90.9)$ & $0(0)$ & $26(100)$ \\
\hline
\end{tabular}

Twenty one out of the 103 participants had no child with 16 of them having malignant lesions, 56 participants had between 1 and 5 children with 24 malignant lesions picked among this category while 26 had between 6 and 10 children among which 12 had malignant lesions. 
Sixty-two cases were diagnosed as suspicious or highly suggestive of malignancy on ultrasound (BIRADS 4 and 5) out of which $10(16.1 \%)$ of the lesions diagnosed as malignant were benign from histology, the gold standard for this study (Table 2).

Mammography picked 54 suspicious or highly suggestive malignant lesions (BIRADS 4 AND 5) out of which, $8(14.8 \%)$ were histologically benign (Table 1$)$. Mammogram could not make any diagnosis in 17 $(16.5 \%)$ out of the 103 cases because the breast tissue was dense and hence had BIRADS category 0 as the final mammogram diagnosis. Out of the 17 cases with no diagnosis on mammography, 6 (35.3\%) had, malignant lesions (Table 2) which were picked up on ultrasound.

All benign lesions (41cases) diagnosed by ultrasonography were benign at histology. There was a total of 62 $(60.2 \%)$ lesions with malignant features on ultrasonography, out of which $52(83.9 \%)$ were true positive and $10(16.1 \%)$ false positive. The false positives were fibrocystic changes, Intraductal papillomas with fibrocystic change, atypical ductal hyperplasia and chronic inflammatory lesions.

Thus ultrasonography had an overall sensitivity of $100 \%(95 \%$ CI of $93.2-100)$ and a specificity of $80.4 \%$ $(95 \%$ CI of $66.9-90.2)$ with a positive predictive value $(+\mathrm{PV})$ of 83.9 and a negative predictive value (-PV) of 100 which are comparable with the findings of Kolb et al ${ }^{6}$ in which sensitivity, specificity, negative and positive predictive values and accuracy of ultrasonography were, $75.3 \%, 96.8 \%, 99.7 \%, 20.5 \%$, and $96.6 \%$, respectively.

Regarding mammography, 8 (14.8\%) of the 54 cases with malignant features were histologically benign. The sensitivity of mammography to the index cancer ranges from $63 \%$ to $98 \%{ }^{7}$ which is comparable with the overall sensitivity of mammogram in this study which was $73.0 \%(95 \%$ CI of $60.3-83.4)$ and specificity of $80.0 \%(95 \%$ CI of $64.4-90.9)$, with a positive predictive value $(+\mathrm{PV})$ of 85.2 and with a negative predictive value (-PV) of $65.3 .{ }^{6,8}$. These findings ae summarized in Table 3.

Table 3 Summary of sensitivity and specificity of ultrasound and mammogram

\begin{tabular}{|l|l|l|}
\hline & Ultrasound & Mammogram \\
\hline Sensitivity(95\%CI*) & $100 \%(93.2-100)$ & $73.0 \%(60.3-83.4)$ \\
\hline $\begin{array}{l}\text { Specificity(95\%CI*) } \\
\text { Positive Predictive value (+PV) } \\
(\mathbf{9 5 \%} \text { CI*) }\end{array}$ & $80.4 \%(66.9-90.2)$ & $80.0 \%(64.4-90.9)$ \\
\hline $\begin{array}{l}\text { Negative Predictive value (-PV) } \\
(\mathbf{9 5 \%} \text { CI*) }\end{array}$ & $100 \%(91.4-92.0)$ & $85.2 \%(72.9-93.4)$ \\
\hline \multicolumn{2}{|c|}{ CI* Confidence Interval $^{*}$} & $65.3 \%(50.4-78.3)$ \\
\hline
\end{tabular}

\section{DISCUSSION}

The study has demonstrated that breast cancer diagnostic tools - clinical diagnosis, ultrasonography and mammography are largely sensitive in identifying malignant disease. The proportion and age characteristics of malignant breast cancer cases enrolled in the study were comparable with a study by Wiredu et $\mathrm{al}^{4}$ and Huo et al. ${ }^{22}$ In our study the definition of malignancy was made using histology as the gold standard. Sensitivity of clinical diagnosis varied similar to the findings by Kolb et al. ${ }^{23}$ Pain had a sensitivity of $71.2 \%$ in our study which is higher than in a study by Jumah et $\mathrm{al}^{24}$ in Korle $\mathrm{Bu}$ Teaching Hospital, Ghana, where pain had an overall sensitivity of $2 \%$.

The variation may be as a result of their inclusion criteria which did not include those with palpable masses but in our study, some of the cases presenting with pain in addition had other symptoms like ulceration, bloody nipple discharge and masses. In a study by CleggLamptey et al ${ }^{25}$, breast pain in combination with other symptoms like breast lump and nipple discharge when compared to breast pain as the sole symptom was associated with a higher incidence of breast cancer $(16 \%$ and $1.24 \%$ respectively). Patients with breast pain therefore should always have breast examination and not simply reassured.

Early age at menarche has been known for many years to be associated with increased risk of breast cancer ${ }^{9}$ with women who first menstruated at age 15 or later having a $23 \%$ lower risk than those with menarche prior to the age of $12 ; 5$ these findings are support in our study where $63.7 \%$ of the malignant lesions picked were in people with menarche before $15 y$ ears. There is a higher relative risk of $1.3 \%$ for premenopausal than menopausal women for breast cancer ${ }^{8}$ and this was in agreement to findings in our study where 36 of the 52 malignant lesions were in premenopausal women.

Several studies ${ }^{23,26}$ have shown decreased mammographic sensitivity in younger women, even after correcting for breast density. In our study where the age range was 30-94 with a mean age of $55( \pm 15)$ years, 17 out of 103 participants $(16.5 \%)$ required additional imaging after their mammograms mostly because the breast was dense and out of these 6(35.3\%) had malignant foci. Hence 6 malignancies were picked from dense breasts out of the 103 study participants accounting for $5.8 \%$.

It has been shown in other studies that increased breast density increases the risk of breast cancer from 2.2 to fivefold when breasts with densest grade are compared with fatty breasts. ${ }^{28,29}$ 
The combination of decreased mammographic sensitivity and increased prevalence of cancer in denser breasts has prompted interest in the investigation of supplemental screening with ultrasonography ${ }^{30}$ or even MR imaging.

The sensitivity of combined mammography and ultrasonography in our study was $100 \%$ which is comparable to several studies. In the screening series of Kolb et al ${ }^{23}$ and in the series of 480 symptomatic patients reported by Houssami et $\mathrm{al}^{31}$, the sensitivity of combined mammography and ultrasonography was $96 \%$ each. Moy et al ${ }^{9}$ reported that $97 \%$ of palpable cancers were depicted with a combination of ultrasonography and mammography.

\section{CONCLUSION}

In conclusion, this study has demonstrated that clinical diagnosis, ultrasound and mammography can potentially predict breast cancer disease with considerable sensitivity and specificity. The sensitivity of clinical diagnosis is $50.5 \%$, mammography is $73.0 \%$ and that of ultrasonography is $100 \%$, with a specificity of mammograms and ultrasound to be $80.0 \%$ and $80.4 \%$ respectively, in this study and hence in resource poor settings where mammogram machines are scarce and the economic costs of this modality present a challenge, breast ultrasound is recommended as the first line of imaging for diagnostic imaging.

\section{REFERENCES}

1. Parkin DM, Fernández LMG. Use of statistics to assess the global burden of breast cancer. Breast J. 2006 Feb;12 Suppl 1:S70-80.

2. Okobia MN, Bunker CH, Okonofua FE, Osime U. Knowledge, attitude and practice of Nigerian women towards breast cancer: a cross-sectional study. World J Surg Oncol. 2006;4:11.

3. Sankaranarayanan R, Swaminathan R, Jayant K, Brenner H. An overview of cancer survival in Africa, Asia, the Caribbean and Central America: the case for investment in cancer health services. IARC Sci Publ. 2011;(162):257-91.

4. Wiredu EK, Armah HB. Cancer mortality patterns in Ghana: a 10-year review of autopsies and hospital mortality. BMC Public Health. 2006;6:159.

5. Bidoli E, Fratino L, Bruzzone S, Pappagallo M, De Paoli P, Tirelli U, et al. Time trends of cancer mortality among elderly in Italy, 1970--2008: an observational study. BMC Cancer. 2012 Oct 2;12(1):443.

6. Ly D, Forman D, Ferlay J, Brinton LA, Cook MB. An international comparison of male and female breast cancer incidence rates. Int J Cancer [Internet]. 2012 Sep 14 [cited 2012 Oct 6]; Available from:

http://www.ncbi.nlm.nih.gov/pubmed/22987302
7. Okobia MN, Bunker CH. Epidemiological risk factors for breast cancer--a review. Niger J Clin Pract. 2005 Jun;8(1):35-42.

8. Brinton LA, Schairer C, Hoover RN, Fraumeni JF. Menstrual Factors and Risk of Breast Cancer. Cancer Investigation. 1988 Jan 1;6(3):245-54.

9. Kelsey JL, Gammon MD, John EM. Reproductive Factors and Breast Cancer. Epidemiol Rev. 1993 Jan 1;15(1):36-47.

10. Shibuya K, Mathers CD, Boschi-Pinto C, Lopez $\mathrm{AD}$, Murray CJL. Global and regional estimates of cancer mortality and incidence by site: II. Results for the global burden of disease 2000. BMC Cancer. 2002 Dec 26;2:37.

11. Nyström L, Rutqvist LE, Wall S, Lindgren A, Lindqvist M, Rydén S, et al. Breast cancer screening with mammography: overview of Swedish randomised trials. Lancet. 1993 Apr 17;341(8851):973-8.

12. Lai MS, Yen MF, Kuo HS, Koong SL, Chen TH, Duffy SW. Efficacy of breast-cancer screening for female relatives of breast-cancer-index cases: Taiwan multicentre cancer screening (TAMCAS). Int $J$ Cancer. 1998 Sep 25;78(1):21-6.

13. Clegg-Lamptey JNA, Aduful HK, Yarney J, AduAryee NA, Vanderpuye V, Kyereh M, et al. Profile of breast diseases at a self-referral clinic in Ghana. West Afr J Med. 2009 Mar;28(2):114-7.

14. Kolb TM, Lichy J, Newhouse JH. Occult cancer in women with dense breasts: detection with screening US-diagnostic yield and tumor characteristics. $R a$ diology. 1998;207(1):191-199.

15. Kerlikowske K, Grady D, Barclay J, Sickles EA, Ernster V. Effect of age, breast density, and family history on the sensitivity of first screening mammography. Jama. 1996;276(1):33-38.

16. Kolb TM, Lichy J, Newhouse JH. Comparison of the performance of screening mammography, physical examination, and breast us and evaluation of factors that influence them: An analysis of 27,825 patient evaluations 1. Radiology. 2002;225(1):16575.

17. Liberman L, Morris EA, Dershaw DD, Abramson AF, Tan LK. MR imaging of the ipsilateral breast in women with percutaneously proven breast cancer. American Journal of Roentgenology. 2003;180(4):901-910.

18. Moon WK, Noh D-Y, Im J-G. Multifocal, multicentric, and contralateral breast cancers: bilateral whole-breast US in the preoperative evaluation of patients. Radiology. 2002;224(2):569-576.

19. Hlawatsch A, Teifke A, Schmidt M, Thelen M. Preoperative assessment of breast cancer: sonography versus MR imaging. American journal of roentgenology. 2002;179(6):1493-1501. 
20. Chao T-C, Lo Y-F, Chen S-C, Chen M-F. Prospective sonographic study of 3093 breast tumors. Journal of ultrasound in medicine. 1999;18(5):363-370.

21. Komfo Anokye Teaching Hospital [Internet]. [cited 2017 Dec 5]. Available from: http://www.kathhsp.org/

22. Huo D, Ikpatt F, Khramtsov A, Dangou J-M, Nanda R, Dignam J, et al. Population differences in breast cancer: survey in indigenous African women reveals over-representation of triple-negative breast cancer. J Clin Oncol. 2009 Sep 20;27(27):4515-21.

23. Kolb TM, Lichy J, Newhouse JH. Comparison of the performance of screening mammography, physical examination, and breast US and evaluation of factors that influence them: an analysis of 27,825 patient evaluations. Radiology. 2002 Oct;225(1):165-75.

24. Jumah KB, Obajimi MO, Darko R. Women with painful breasts without palpable masses: do they really need a mammogram? Afr J Med Med Sci. 2003 Dec;32(4):387-9.

25. Clegg-Lamptey JNA, Edusa C, Ohene-Oti N, Tagoe JA. Breast cancer risk in patients with breast pain in Accra, Ghana. East Afr Med J. 2007 May;84(5):215-8.

26. Carney PA, Miglioretti DL, Yankaskas BC, Kerlikowske K, Rosenberg R, Rutter CM, et al. Individual and combined effects of age, breast density, and hormone replacement therapy use on the accuracy of screening mammography. Ann Intern Med. 2003 Feb 4;138(3):168-75.
27. Burhenne HJ, Burhenne LW, Goldberg F, Hislop TG, Worth AJ, Rebbeck PM, et al. Interval breast cancers in the Screening Mammography Program of British Columbia: analysis and classification. AJR American journal of roentgenology. 1994;162(5):1067-1071.

28. Ursin G, Ma H, Wu AH, Bernstein L, Salane M, Parisky YR, et al. Mammographic density and breast cancer in three ethnic groups. Cancer Epidemiol Biomarkers Prev. 2003 Apr;12(4):332-8.

29. Nagao Y, Kawaguchi Y, Sugiyama Y, Saji S, Kashiki Y. Relationship between mammographic density and the risk of breast cancer in Japanese women: a case-control study. Breast Cancer. 2003;10(3):228-33.

30. Berg WA. Rationale for a trial of screening breast ultrasound: American College of Radiology Imaging Network (ACRIN) 6666. AJR Am J Roentgenol. 2003 May;180(5):1225-8.

31. Houssami N, Irwig L, Simpson JM, McKessar M, Blome S, Noakes J. Sydney Breast Imaging Accuracy Study: Comparative sensitivity and specificity of mammography and sonography in young women with symptoms. AJR Am J Roentgenol. 2003 Apr;180(4):935-40.

32. Moy L, Slanetz PJ, Moore R, Satija S, Yeh ED, McCarthy KA, et al. Specificity of mammography and US in the evaluation of a palpable abnormality: retrospective review. Radiology. 2002 Oct;225(1):176-81. 


\section{Original Article}

\section{Appendix 1}

Breast Imaging Reporting and Data System (BI-RADS) lexicon

\begin{tabular}{|c|c|c|}
\hline IMPRESSION & Mammogram Findings/features & $\begin{array}{c}\text { ULTRASONOGRAPHY } \\
\text { Findings/features } \\
\end{array}$ \\
\hline $\begin{array}{l}\text { Category } 0 \\
\text { (needs additional imaging } \\
\text { evaluation) }\end{array}$ & $\begin{array}{l}\text { No diagnosis could be made based on the conven- } \\
\text { tional mammogram taken; mostly due to dense } \\
\text { breast or subtle changes where no conclusion can } \\
\text { be made due to findings and hence requires addi- } \\
\text { tional imaging like spot view or ultrasonography }\end{array}$ & \\
\hline $\begin{array}{l}\text { Category } 1 \\
\text { (negative- nothing to com- } \\
\text { ment on) }\end{array}$ & No abnormality; no malignant or benign features & $\begin{array}{l}\text { No abnormality was detected; } \\
\text { no malignant or benign fea- } \\
\text { tures. }\end{array}$ \\
\hline $\begin{array}{l}\text { Category } 2 \\
\text { (Benign finding) }\end{array}$ & $\begin{array}{l}\text { Masses with the following features; Oval or } \\
\text { round shape mass with Smooth, sharp or well- } \\
\text { defined margins, iso-dense or hypo-dense mass to } \\
\text { breast tissue; lucent or fatty content mass; macro } \\
\text { calcifications or 'popcorn' calcifications }\end{array}$ & $\begin{array}{l}\text { lesion with the following } \\
\text { features; Oval or round } \\
\text { shape; Smooth, sharp or } \\
\text { well-defined margins; hyper } \\
\text { echoic or mildly hypo echoic } \\
\text { to breast tissue mass; fatty } \\
\text { content in mass; macro calci- } \\
\text { fications or 'popcorn' calcifi- } \\
\text { cations; homogeneous echo } \\
\text { texture; no posterior shadow- } \\
\text { ing; bilateral edge shadow- } \\
\text { ing; compressible; longer } \\
\text { than taller. }\end{array}$ \\
\hline $\begin{array}{l}\text { Category } 3 \\
\text { (Probably benign finding) }\end{array}$ & $\begin{array}{l}\text { Lesions with more of benign features but showed } \\
\text { even one of the malignant features were consid- } \\
\text { ered to be probably benign and required a short- } \\
\text { term interval follow-up. }\end{array}$ & $\begin{array}{l}\text { Lesions with more of benign } \\
\text { features but showed even one } \\
\text { of malignant feature were } \\
\text { considered to be probably } \\
\text { benign }\end{array}$ \\
\hline $\begin{array}{l}\text { Category } 4 \\
\text { (Suspicious abnormality) }\end{array}$ & $\begin{array}{l}\text { Lesions with more of malignant features and } \\
\text { showed even one benign feature were considered } \\
\text { as suspicious of malignancy and needed to be } \\
\text { biopsied }\end{array}$ & $\begin{array}{l}\text { Lesions with more of malig- } \\
\text { nant features but showed } \\
\text { even one of the benign fea- } \\
\text { tures were considered as sus- } \\
\text { picious of malignancy, and } \\
\text { required biopsy. }\end{array}$ \\
\hline $\begin{array}{l}\text { Category } 5 \\
\text { (Highly suggestive of malig- } \\
\text { nancy) }\end{array}$ & $\begin{array}{l}\text { Masses with ill-defined, irregular or obscured } \\
\text { margins; spiculated or micro lobulated contour or } \\
\text { margin; markedly dense; retracted nipple; skin } \\
\text { thickening; architectural distortion; pleomorphic } \\
\text { micro calcifications. }\end{array}$ & $\begin{array}{l}\text { Lesions with features as fol- } \\
\text { lows; ill-defined; irregular or } \\
\text { micro lobulated contour or } \\
\text { margin; markedly hypo echo- } \\
\text { ic mass; heterogeneous echo } \\
\text { texture; taller than longer; } \\
\text { posterior shadowing; non- } \\
\text { compressible. }\end{array}$ \\
\hline
\end{tabular}

